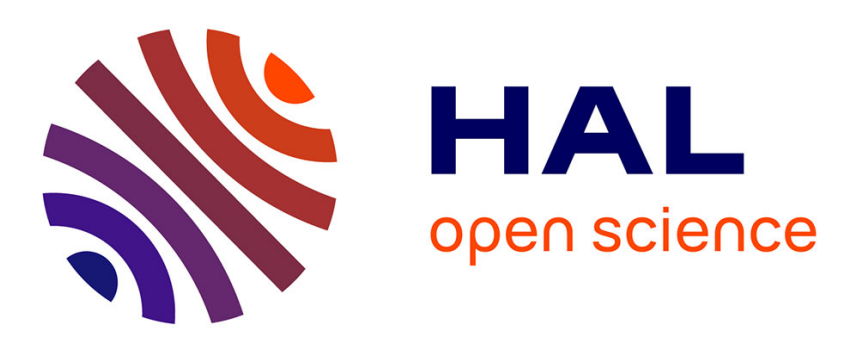

\title{
Is Exercise-Induced Arterial Hypoxemia in Triathletes Dependent on Exercise Modality?
}

\author{
Olivier Galy, Alain Boussana, Olivier Hue, Daniel Le Gallais, Christian \\ Prefaut
}

\section{- To cite this version:}

Olivier Galy, Alain Boussana, Olivier Hue, Daniel Le Gallais, Christian Prefaut. Is Exercise-Induced Arterial Hypoxemia in Triathletes Dependent on Exercise Modality?. International Journal of Sports Medicine, 2005, 26 (9), pp.719-726. 10.1055/s-2005-837446 . hal-00720806

\section{HAL Id: hal-00720806 https://hal.univ-antilles.fr/hal-00720806}

Submitted on 25 Jul 2012

HAL is a multi-disciplinary open access archive for the deposit and dissemination of scientific research documents, whether they are published or not. The documents may come from teaching and research institutions in France or abroad, or from public or private research centers.
L'archive ouverte pluridisciplinaire HAL, est destinée au dépôt et à la diffusion de documents scientifiques de niveau recherche, publiés ou non, émanant des établissements d'enseignement et de recherche français ou étrangers, des laboratoires publics ou privés. 


\section{O. Galy ${ }^{1}$ \\ D. Le Gallais ${ }^{2}$ \\ O. Hue ${ }^{1}$ \\ A. Boussana ${ }^{2}$ \\ Is Exercise-Induced Arterial Hypoxemia in Triathletes \\ C. Préfaut ${ }^{3}$ Dependent on Exercise Modality?}

\begin{abstract}
To determine whether exercise modality affects arterial hypoxemia (EIAH) during training-intensity exercise, 13 triathletes performed 20 min of cycling (C) followed by 20 min of running (R): C-R, and two weeks later, 20 min of R followed by 20 min of C: RC. Each trial was performed at an intensity slightly above the ventilatory threshold and close to the daily training intensity ( $75 \%$ of $\dot{\mathrm{VO}}_{2 \max }$ ). Ventilatory data were collected continuously using an automated breath-by-breath system. Partial pressure of oxygen in arterial blood $\left(\mathrm{PaO}_{2}\right)$ was measured after each $\mathrm{C}$ and $\mathrm{R}$ segment and arterial oxyhemoglobin saturation $\left(\mathrm{SpO}_{2}\right)$ was monitored continuously via pulse oximetry. The metabolic rate was similar across modalities and trials, i.e., C-R (53.8 \pm 3.8 vs. $\left.51.1 \pm 5.3 \mathrm{ml} \cdot \mathrm{min}^{-1} \cdot \mathrm{kg}^{-1}\right)$ and $\mathrm{R}-\mathrm{C}(52.2 \pm 4.5$ vs. $53.2 \pm$ $\left.4.6 \mathrm{ml} \cdot \mathrm{min}^{-1} \cdot \mathrm{kg}^{-1}\right)$. EIAH showed significantly greater severity for $\mathrm{R}$ compared to $\mathrm{C}$ irrespective of the order $(\mathrm{p}<0.05$ for both
\end{abstract}

trials). $\mathrm{R}$ values of $\mathrm{PaO}_{2}$ (and $\mathrm{SpO}_{2}$ ) for $\mathrm{C}-\mathrm{R}$ and $\mathrm{R}-\mathrm{C}$ were $88.7 \pm 6.0 \mathrm{~mm} \mathrm{Hg} \quad\left(93.0 \pm 0.6 \% \quad \mathrm{SpO}_{2}\right)$ and $86.6 \pm 7.3 \mathrm{~mm} \mathrm{Hg}$ $\left(93.5 \pm 0.6 \% \mathrm{SpO}_{2}\right)$ and $\mathrm{C}$ values were $93.7 \pm 8.4 \mathrm{~mm} \mathrm{Hg}(95.4 \pm$ $\left.0.4 \% \mathrm{SpO}_{2}\right)$ and $91.4 \pm 5.4 \mathrm{~mm} \mathrm{Hg}\left(94.8 \pm 0.3 \% \mathrm{SpO}_{2}\right)$. R ventilatory data described a significantly different breathing pattern than $\mathrm{C}$, with higher respiratory rate $\left(35.9 \mathrm{~b} \cdot \mathrm{min}^{-1} \mathrm{vs} .51 .1 \mathrm{~b} \cdot \mathrm{min}^{-1}\right.$ for C$\mathrm{R}, \mathrm{p}<0.01$; and $50.0 \mathrm{~b} \cdot \mathrm{min}^{-1}$ vs. $41.5 \mathrm{~b} \cdot \mathrm{min}^{-1}$ for $\mathrm{R}-\mathrm{C}, \mathrm{p}<0.01$ ) and lower tidal volume ( $2636 \mathrm{ml}$ vs. $2282 \mathrm{ml}$ for $\mathrm{C}-\mathrm{R}, \mathrm{p}<0.02$ and $2272 \mathrm{ml}$ vs. $2472 \mathrm{ml}$ for $\mathrm{R}-\mathrm{C}, \mathrm{p}<0.05)$. We concluded that EIAH was greater during running than cycling for a similar metabolic rate corresponding to training intensity and that EIAH could thus be considered dependent on exercise modality.

\section{Key words}

Pulmonary gas exchanges · EIAH · DLCO - endurance training · breathing pattern $\cdot$ triathlon

\section{Introduction}

Exercise-induced arterial hypoxemia (EIAH) is frequent in highly trained male endurance athletes with a maximal oxygen uptake $\left(\mathrm{V}_{2 \max }\right)$ greater than $55 \mathrm{ml} \cdot \mathrm{min}^{-1} \cdot \mathrm{kg}^{-1}[5,24]$. Different endurance activities are well known to generate EIAH, particularly cycling, running, swimming, rowing, and the triathlon $[3,11,24$, $29,32]$. Recent studies $[10,30]$ have shown a greater drop in the partial pressure of oxygen in arterial blood $\left(\mathrm{PaO}_{2}\right)$ or in arterial oxyhemoglobin saturation $\left(\mathrm{SpO}_{2}\right)$ at both maximal [10] and submaximal exercise [30] during treadmill running compared with ergometer cycling, which suggests that EIAH is dependent on exercise modality. However, a concomitant higher $\dot{\mathrm{VO}}_{2 \max }$ for treadmill running than for ergometer cycling has also been observed, with $\mathrm{VO}_{2}$ values inversely related to $\mathrm{SpO}_{2}$ level during maximal and submaximal exercise $[28,34]$. Unfortunately, these latter studies did not clearly indicate whether the difference in $\mathrm{SpO}_{2}$ between the two activities was associated with the difference in 
$\dot{\mathrm{V}} \mathrm{O}_{2}$ or with the activity per se, thereby leaving the question of EIAH's dependency on exercise modality open.

EIAH is a multifactorial phenomenon $[6,27]$ and in both cycling and running, it is usually attributed to two main mechanisms: a relative hypoventilation [5] and/or an alteration in pulmonary gas exchange, i.e., ventilation/perfusion mismatching and/or diffusion limitation [4]. Relative hypoventilation has been suggested to be the predominant factor at submaximal exercise intensity and may be present in all highly trained athletes $[6,20]$. In addition, the higher ventilatory components observed in triathletes during running compared to cycling have systematically been related to the higher EIAH of running $[8,9,18]$.

This study aimed (1) to determine whether EIAH is dependent on exercise modality and (2) to evaluate the role of the two principal mechanisms, particularly relative hypoventilation, in regard to modality. Triathletes, who are skilled at both cycling and running, performed a constant submaximal cycle-run succession, as well as an inverse run-cycle succession. Both trials were conducted at the same metabolic rate, which was close to the athletes' daily training intensity. We hypothesised that running would induce greater EIAH than cycling, whatever the modality order, as previously reported for maximal exercise.

\section{Methods}

\section{Subjects}

Thirteen male competitive triathletes participated in this study. All were students at the School of Physical Education of the University of Montpellier, France, as well as members of the University athletic team, which has been French national champion in the triathlon for five consecutive years. Some were on the national federation team. All had been competing in the triathlon for $6.3 \pm 2.8$ years and were in the competitive period at the time of the study. They were $22.3 \pm 3.2$ years old, weighed $67.5 \pm 6.3 \mathrm{~kg}$ and measured $176.3 \pm 6.8 \mathrm{~cm}$ in height. All were non-smokers with normal lung function and no prior history of pulmonary or cardiovascular disease. These triathletes were familiar with both the treadmill and cycle ergometer. They gave written consent to participate in this study after the purpose, design, and risks had been described to them. The study protocol was in accordance with legal requirements and the Declaration of Helsinki, and it was approved by the regional ethics committee.

\section{Testing protocol}

An incremental cycle test was first performed on an electromagnetic cycle ergometer (Monark 864, Monark-Crescent AB, Varburg, Sweden) to assess maximal oxygen uptake $\left(\dot{\mathrm{VO}}_{2 \max }\right)$ and ventilatory threshold $\left(\mathrm{Th}_{\mathrm{vent}}\right)$. Three to seven days later, the triathletes performed two constant submaximal exercises consisting of a cycle-run (C-R) succession and an inverse run-cycle (RC) succession of $40 \mathrm{~min}$ each; these successions were performed within a two-week period. The incremental test and the trials were conducted in an air-conditioned laboratory with a mean room temperature of $21.9 \pm 0.2^{\circ} \mathrm{C}$ and a barometric pressure of $777.5 \pm 4.5 \mathrm{~mm} \mathrm{Hg}$. Trials were randomised and performed at the same time of day and on the same day of the week to minimise the effects of circadian rhythms and personal training. The triathletes were asked to maintain their training schedule for the duration of the study but they were not allowed to compete in a triathlon during the testing period. The triathletes were also asked to refrain from training on experimental days. The protocol of the incremental cycle test started with a 3-min warm-up at $30 \mathrm{~W}$. The power was then increased by $30 \mathrm{~W}$ every minute until each subject reached volitional fatigue. All triathletes reached their maximal oxygen uptake with: (1) a levelling-off of $\dot{\mathrm{VO}}_{2}$ despite increasing load, (2) a respiratory exchange ratio (RER) greater than 1.10, (3) attainment of age-predicted maximal heart rate $(\mathrm{HR}) \pm 5 \%$ ( $210-[0.65$ age]), and (4) the inability to maintain pedalling frequency despite maximum effort and verbal encouragement. $\mathrm{Th}_{\mathrm{vent}}$ was determined using the $\dot{\mathrm{V}}$-slope method of Beaver et al. [1], which analyses carbon dioxide production $\left(\dot{\mathrm{V} C O}{ }_{2}\right)$ as a function of $\dot{\mathrm{VO}}_{2}$ and assumes that $\mathrm{Th}_{\text {vent }}$ corresponds to the breakpoint in the $\dot{\mathrm{V}} \mathrm{CO}_{2}-\dot{\mathrm{V}}_{2}$ relationship. Because our group has demonstrated that incremental cycling and running $\dot{\mathrm{VO}}_{2 \max }$ are similar in young triathletes without prior athletic specialisation [19] - which was the case of the triathletes of the present study - the cycling $\dot{\mathrm{V}}_{2 \text { max }}$ value was used to express the metabolic rate of both the cycling and running segments of the two trials, i.e., about $75 \%$ of $\dot{\mathrm{VO}}_{2 \mathrm{max}}$, an intensity that is higher than $\mathrm{Th}_{\mathrm{vent}}$. During C-R and R-C, the R and C segments were managed in order to maintain this level for the duration of the trials. The triathletes used their own cycles on a home trainer (Pro Training, Pro Trainer, Milan, Italy), and each cycle was equipped with a profiled handlebar commonly used during the cycle segment of a triathlon. The $\mathrm{VO}_{2}$ level was progressively reached by the end of the third minute and then maintained by increasing or decreasing the cycling speed by $1 \mathrm{~km} \cdot \mathrm{h}^{-1}$ every minute. Distances were recorded with a bike odometer (Top Bike, Tokyo, Japan). After the cycle segment, the triathletes had $1 \mathrm{~min} 30 \mathrm{~s}$ to change their shoes and get on the treadmill. During running (Gymroll 1800, Gymroll, Roche la Molière, France), the $\dot{\mathrm{VO}}_{2}$ level again rose progressively and was attained by the end of the third minute. It was then maintained by increasing or decreasing the running speed by $0.5 \mathrm{~km} \cdot \mathrm{h}^{-1}$ every minute. Distances were recorded with the treadmill odometer. After the running segment of $\mathrm{R}-\mathrm{C}$, the triathletes had $1 \mathrm{~min} 30 \mathrm{~s}$ to change their shoes and get on their bicycle.

\section{Complementary experiment}

Two complementary randomised trials were performed by three volunteer triathletes. The first consisted of $10 \mathrm{~min}$ of cycling with a spontaneous breathing pattern $\left(\mathrm{C}_{1}\right)$, followed by $10 \mathrm{~min}$ of cycling with an imposed breathing pattern corresponding to that of running (CR) during C-R and R-C, then 5 min of cycling with a spontaneous breathing pattern $\left(C_{2}\right)$. The second trial consisted of 10 min of running with a spontaneous breathing pattern $\left(R_{1}\right)$, followed by 10 min of running with an imposed breathing pattern similar to that of cycling $\left(R_{C}\right)$ during $C-R$ and $R-C$, then 5 min of running with a spontaneous breathing pattern $\left(R_{2}\right)$. During $C_{R}$ and $R_{C}, R R$ was imposed on the triathletes using an electronic metronome as auditory feedback. In contrast to RR, VT was not monitored. These two trials were performed at the same metabolic rate and in the same general and ambient conditions as C$\mathrm{R}$ and $\mathrm{R}-\mathrm{C}$. 


\section{Percent $\mathrm{SpO}_{2}$}

Arterial oxyhemoglobin saturation $\left(\mathrm{SpO}_{2}\right)$ was assessed continuously and recorded every minute during the incremental cycle test and the C-R and R-C successions, using an ear pulse oximeter (Ohmeda 3740 Pulse Oximeter, Louisville, USA). This method has been reported to deliver high precision, reproducibility, and validity for $\mathrm{O}_{2}$ saturation above $85 \%$ when compared to $\mathrm{SaO}_{2}$ measured from arterial blood gases in highly trained athletes [21], with $0.52 \pm 1.36 \%$ (standard deviation) of the difference in mean $\% \mathrm{SaO}_{2}-\% \mathrm{HbO}_{2}$ and a standard error of the estimate $=1.32 \%$ at submaximal exercise. Moreover, the Ohmeda 3740 Pulse Oximeter is highly accurate when placed on the ear lobe at maximal exercise, as well as during submaximal exercise [21]. The instrument's conducting cable was secured to prevent movement artefacts, especially during running, and the oximeter was calibrated before each experiment using an internal calibration. Before the probes were placed, the sites were vigorously cleaned with alcohol and gauze pads. The oximeter's poor signal alarm and pulse waveform were closely monitored by the recording investigator to ensure that spurious data were not included. Athletes were considered to have developed EIAH when $\mathrm{SpO}_{2}$ decreased by at least $4 \%$ from baseline value [27].

\section{Blood gas measurements}

In order to confirm the $\mathrm{SpO}_{2}$ data and to calculate alveolar ventilation, arterialised blood samples were obtained from the ear lobe at rest and at the 20th and 40th minutes of C-R and R-C. Before sampling, the ear lobe was warmed up by massage to activate arterialised circulation. Arterialised blood samples are known to give reliable values, as was demonstrated in recent works of our group $[8,18]$. These samples were immediately analysed for $\mathrm{PaO}_{2}$, the partial arterial pressure of carbon dioxide $\left(\mathrm{PaCO}_{2}\right)$, and $\mathrm{pH}$ at $37^{\circ} \mathrm{C}$ using an appropriate electrode (IL Meter 1306, Milan, Italy). The instrument was calibrated prior to each measurement with the same gas mixture as for the expired gas analysers. Given the variability in $\mathrm{PaO}_{2}$ measurement, resting hypoxemia should be defined as a drop of $5 \mathrm{~mm} \mathrm{Hg}$ in $\mathrm{PaO}_{2}$ [25]. During exercise, the decrease in $\mathrm{PaO}_{2}$ may be overestimated because of a rise in body temperature. Our arterialised blood gas values are presented for a temperature of $37^{\circ} \mathrm{C}$ because we assumed that the 40-min exercise duration would not raise rectal temperature since (1) the laboratory was air-conditioned $\left(21.9^{\circ} \mathrm{C}\right)$ and $(2)$ when exercise in triathletes was performed at $70 \%$ of $\mathrm{V}_{2 \max }$ with an ambient temperature of $29^{\circ} \mathrm{C}$, the increase in rectal temperature was 0.2 and $0.5^{\circ} \mathrm{C}$ after 20 and $40 \mathrm{~min}$ of cycling and 0.5 and $1.0^{\circ} \mathrm{C}$ after 20 and $40 \mathrm{~min}$ of running [20]. Therefore, to minimise the risk of overestimating EIAH due to an increase in body temperature estimated to be about $0.5^{\circ} \mathrm{C}$, we added $3 \mathrm{~mm} \mathrm{Hg}$ to the $5 \mathrm{~mm} \mathrm{Hg}$ drop in $\mathrm{PaO}_{2}$ commonly used to define hypoxemia during exercise [25], i.e., a drop of $8 \mathrm{~mm} \mathrm{Hg}$ in $\mathrm{PaO}_{2}$. Lastly, to account for the error caused by the lag between rectal temperature and blood temperature, i.e., $2 \mathrm{~mm} \mathrm{Hg}$ [15], we defined EIAH as a minimum drop of $10 \mathrm{~mm} \mathrm{Hg}$ in $\mathrm{PaO}_{2}$. Arterialised blood gases were drawn and carbon dioxide production $\left(\mathrm{V} \mathrm{CO}_{2}\right)$ was computed during the last $20 \mathrm{~s}$ of treadmill running and ergometer cycling during the trials. This allowed us to calculate alveolar ventilation (VंA) using the Bohr equation, where $\dot{\mathrm{V}} \mathrm{A}_{(\mathrm{BTPS})}=863 \cdot \dot{\mathrm{V}} \mathrm{CO}_{2(\mathrm{STPD})} / \mathrm{PaCO}_{2}$. In this equation, $\dot{\mathrm{V} C \mathrm{CO}_{2}}$ was calculated with the mean values at the 19th minute of each segment, i.e., $C$ and $R$.

\section{Pulmonary diffusing capacity}

All subjects rested in the seated position for $10 \mathrm{~min}$ before measurement of pulmonary diffusing capacity for carbon monoxide (DLco). The DLco was measured during breath-holding (single breath method) while seated, using an automated transfer apparatus before and 10 min after C-R and R-C (Transfer Test, Morgan, Chatham, Kent, UK). After a full exhalation, subjects inhaled a gas mixture $\left(10 \% \mathrm{He}, 21 \% \mathrm{O}_{2}\right.$, and $2.800 \mathrm{ppm} \mathrm{CO}$, in $\left.\mathrm{N}_{2}\right)$, held their breath for $9 \mathrm{~s}$, and finally executed a rapid exhalation (American Thoracic Society 1987). DLco measurements were made by the same operator in triplicate.

\section{Gas exchange measurements}

During incremental cycle testing, as well as the C-R and R-C successions, ventilatory data were computed every minute using a mass spectrometer breath-by-breath automated system (MGA1100, Marquette, NY, USA): minute ventilation (V̉E), oxygen uptake $\left(\dot{\mathrm{VO}}_{2}\right), \dot{\mathrm{V}} \mathrm{CO}_{2}$, respiratory exchange ratio (RER), respiratory equivalents for $\mathrm{O}_{2}\left(\dot{\mathrm{VE}} / \mathrm{VO}_{2}\right)$ and $\mathrm{CO}_{2}\left(\dot{\mathrm{V}} / \mathrm{V} / \mathrm{VO}_{2}\right)$, respiratory rate (RR), and tidal volume (VT). The VD/VT ratio was also calculated (from the equation $\mathrm{VD} / \mathrm{VT}+\dot{\mathrm{V} A} / \mathrm{V} E=1$ ). The gas analysers were calibrated before each trial with standard $\mathrm{O}_{2}$ and $\mathrm{CO}_{2}$ gases of known concentration using a certified commercial gas preparation. Heart rate (HR) was recorded using a telemetry system (Polar Sport Tester, Polar Electro Oy, Kempele, Finland).

\section{Statistical analysis}

The results are expressed as means $\pm \mathrm{SD}$. Running and cycling distances during C-R and R-C were compared using a paired Student $t$-test. After verification of a normal distribution (Gaussian graphical distribution), $\mathrm{SpO}_{2}, \mathrm{PaO}_{2}, \mathrm{PAO}_{2}, \mathrm{PaCO}_{2}, \mathrm{VA},(\mathrm{A}-\mathrm{a}) \mathrm{DO}_{2}$, $\mathrm{pH}$, and the cardioventilatory data $\left(\dot{\mathrm{V}}_{2}, \dot{\mathrm{VE}}, \mathrm{RER}, \dot{\mathrm{VE}} / \dot{\mathrm{VO}}_{2}, \dot{\mathrm{VE}} /\right.$ $\dot{\mathrm{V}} \mathrm{CO}_{2}, \mathrm{VT}, \mathrm{VD} / \mathrm{VT}$, RR, and $\mathrm{HR}$ ), which had been recorded throughout the two trials and complementary trials, were compared using a two-way analysis (exercise - time) of variance (ANOVA) with repeated measures. When significant results were obtained with ANOVA, post-hoc comparisons were made using Scheffe's posthoc test [35]. DLco measurements were compared after versus before the two trials to analyse the influence of specific exercise on DLco using a one-way ANOVA. Statistical analysis was performed using a statistical software package (SYSTAT). Statistical significance was accepted at the $\mathrm{p}<0.05$ level.

\section{Results}

\section{Exercise intensities}

The incremental exercise test revealed a $\dot{\mathrm{VO}}_{2 \max }$ of $69.9 \pm$ $3.3 \mathrm{ml} \cdot \mathrm{min}^{-1} \cdot \mathrm{kg}^{-1}$ for the triathletes. C-R and $\mathrm{R}-\mathrm{C}$ showed no significant difference in running and cycling distances: $12.6 \pm 0.9 \mathrm{~km}$ versus $11.9 \pm 1.9 \mathrm{~km}$ for cycling and $6.5 \pm 0.2 \mathrm{~km}$ versus $6.5 \pm 0.2 \mathrm{~km}$ for running, respectively (Tables $\mathbf{1}$ and $\mathbf{2}$ ). Metabolic rate (and \% of $\mathrm{VO}_{2 \max }$ ) during C-R and R-C were similar, with $53.8 \pm 3.8 \mathrm{ml} \cdot \mathrm{min}^{-1} \cdot \mathrm{kg}^{-1}\left(77 \pm 5.4 \%\right.$ of $\left.\dot{\mathrm{V}} \mathrm{O}_{2 \max }\right), 51.1 \pm 5.3 \mathrm{ml}$. $\mathrm{min}^{-1} \cdot \mathrm{kg}^{-1} \quad\left(73 \pm 5.6 \%\right.$ of $\left.\dot{\mathrm{VO}} \mathrm{O}_{\text {max }}\right), \quad 52.2 \pm 4.5 \mathrm{ml} \cdot \mathrm{min}^{-1} \cdot \mathrm{kg}^{-1}$ $\left(74.6 \pm 6.4 \%\right.$ of $\left.\dot{\mathrm{V}} \mathrm{V}_{2 \max }\right)$, and $53.2 \pm 4.6 \mathrm{ml} \cdot \mathrm{min}^{-1} \cdot \mathrm{kg}^{-1}(76.1 \pm$ $6.1 \%$ of $\dot{\mathrm{V}}_{2 \max }$ ), respectively (Table $\mathbf{1}$ ). 
Table $1 \mathrm{SpO}_{2}$ and cardioventilatory parameters recorded during C$\mathrm{R}$ and $\mathrm{R}-\mathrm{C}$

\begin{tabular}{|c|c|c|c|c|}
\hline & C & $R$ & $R$ & $c$ \\
\hline $\mathrm{SpO}_{2}(\%)$ & $\begin{array}{r}95.4 \\
1.4\end{array}$ & $\begin{array}{c}93.0^{* *} \\
2.3\end{array}$ & $\begin{array}{c}93.5^{* *} \\
1.0\end{array}$ & $\begin{array}{c}94.8^{*} \\
2.2\end{array}$ \\
\hline$\dot{V O O}_{2}\left(\mathrm{ml} \cdot \mathrm{min}^{-1} \cdot \mathrm{kg}^{-1}\right)$ & $\begin{array}{r}53.8 \\
3.8\end{array}$ & $\begin{array}{r}51.1 \\
5.3\end{array}$ & $\begin{array}{r}52.2 \\
4.5\end{array}$ & $\begin{array}{r}53.2 \\
4.6\end{array}$ \\
\hline$\% \dot{V O}_{2 \max }$ cycling & $\begin{array}{r}77.0 \\
5.4\end{array}$ & $\begin{array}{r}73.0 \\
7.6\end{array}$ & $\begin{array}{r}74.6 \\
6.4\end{array}$ & $\begin{array}{r}76.1 \\
6.1\end{array}$ \\
\hline$\dot{V E}\left(I \cdot \mathrm{min}^{-1}\right)$ & $\begin{array}{l}93.3 \\
12.5\end{array}$ & $\begin{array}{c}113.5^{*} \\
10.7\end{array}$ & $\begin{array}{c}106.9^{*} \\
13.3\end{array}$ & $\begin{array}{r}100.8 \\
14.0\end{array}$ \\
\hline $\mathrm{VE} / \mathrm{VO}_{2}$ & $\begin{array}{r}21.7 \\
2.3\end{array}$ & $\begin{array}{c}28.6^{*} \\
4.9\end{array}$ & $\begin{array}{c}26.1^{*} \\
4.1^{2}\end{array}$ & $\begin{array}{r}24.0 \\
2.9\end{array}$ \\
\hline$\dot{\mathrm{V}} / \dot{\mathrm{VCO}}{ }_{2}$ & $\begin{array}{r}22.9 \\
2.2\end{array}$ & $\begin{array}{c}30.2^{*} \\
4.9\end{array}$ & $\begin{array}{c}27.3^{*} \\
4.1\end{array}$ & $\begin{array}{r}25.0 \\
3.0\end{array}$ \\
\hline RER & $\begin{array}{l}0.94 \\
0.03\end{array}$ & $\begin{array}{l}0.94 \\
0.02\end{array}$ & $\begin{array}{l}0.96 \\
0.03\end{array}$ & $\begin{array}{l}0.96 \\
0.02\end{array}$ \\
\hline$R R$ (breath $\cdot \mathrm{min}^{-1}$ ) & $\begin{array}{r}35.9 \\
5.7\end{array}$ & $\begin{array}{c}51.1^{*} \\
5.7\end{array}$ & $\begin{array}{c}50.0^{*} \\
6.9\end{array}$ & $\begin{array}{r}41.5 \\
6.0\end{array}$ \\
\hline$V T(m l)$ & $\begin{array}{r}2636 \\
362\end{array}$ & $\begin{array}{c}2282^{* *} \\
398\end{array}$ & $\begin{array}{c}2272^{* *} \\
322\end{array}$ & $\begin{array}{r}2472 \\
397\end{array}$ \\
\hline$H R\left(b \cdot \min ^{-1}\right)$ & $\begin{array}{c}154 \\
9.8\end{array}$ & $\begin{array}{r}171^{*} \\
7.5\end{array}$ & $\begin{array}{r}166 \\
6.5\end{array}$ & $\begin{array}{r}167 \\
6.5\end{array}$ \\
\hline
\end{tabular}

Values are mean \pm SD. ${ }^{*} p<0.05$ significantly higher compared to $C$ inside trials. ${ }^{* *} \mathrm{p}<0.05$ significantly lower compared to $C$ within $C-R$ and $R-C$

\section{Percent $\mathrm{SpO}_{2}$}

During incremental exercise, $\mathrm{SpO}_{2}$ decreased from $99 \pm 0.2 \%$ (resting value) to $93.4 \pm 1.8 \%$ (range $90-95 \%$ ), thereby demonstrating EIAH. During C-R and R-C, all triathletes presented a significant drop in $\mathrm{SpO}_{2}$ compared with the resting values (Fig.1). The mean values presented in Table 1 show a significant drop
Zeitschrift IJSM sm290

AK-PDF tt.mm.jj

ef-Upload tt.mm.jj
Satzbetrieb Ziegler + Müller

Verlag Thieme/Hentze

Datum 21.01.2005

from rest values throughout the entire $C-R$ and $R-C$ trials, with a $\mathrm{p}<0.05$. Moreover, this drop was significantly more pronounced during $\mathrm{R}$ when compared to $\mathrm{C}$ within each trial. The amplitude of the drop was $-6 \pm 2.2 \%$ and $-5.8 \pm 2.0 \%$ during running $(\mathrm{p}<0.01)$ and $-3.9 \pm 1.1 \%$ and $-4.1 \pm 1.0 \%$ during cycling of C-R and R-C, respectively (Fig. 1).

\section{Blood gas measurements}

A significant drop from resting values in $\mathrm{PaO}_{2}$ and $\mathrm{PaCO}_{2}$ was noted after $\mathrm{C}-\mathrm{R}$ and $\mathrm{R}-\mathrm{C}$ (Table 2 ). The drop in $\mathrm{PaO}_{2}$ was significantly greater during running $(-15.1 \pm 3.2 \mathrm{mmHg}$ and $-20.3 \pm 11.0 \mathrm{~mm} \mathrm{Hg})$ than during cycling $(-10.2 \pm 2.2 \mathrm{~mm} \mathrm{Hg}$ and $-16.0 \pm 11.2 \mathrm{~mm} \mathrm{Hg}$ ) in the $\mathrm{C}-\mathrm{R}$ and $\mathrm{R}-\mathrm{C}$ trials, respectively. Moreover, the significantly greater drop in $\mathrm{PaO}_{2}$ noted during running was concomitant with significantly lower $\dot{V A}$ values (Table 2 ).

$\mathrm{PAO}_{2}$ and $(\mathrm{A}-\mathrm{a}) \mathrm{DO}_{2}$ increased during $\mathrm{C}-\mathrm{R}$ when compared to rest values, whereas only (A-a) $\mathrm{DO}_{2}$ increased during $\mathrm{R}-\mathrm{C}$ (Table $\mathbf{2}$ ). Moreover, a significant difference was observed between $C$ and $\mathrm{R}$ of $\mathrm{C}-\mathrm{R}$, with a higher $(\mathrm{A}-\mathrm{a}) \mathrm{DO}_{2}$ during successive $\mathrm{R}$. The $\mathrm{pH}$ values only decreased during $C$ of $C-R$, showing a significant drop compared to both rest and successive R.

\section{Respiratory parameters}

The two trials were characterised by higher $\dot{\mathrm{VE}}, \dot{\mathrm{V} E} / \dot{\mathrm{V}} \mathrm{O}_{2}, \dot{\mathrm{VE}} / \dot{\mathrm{V}} \mathrm{CO}_{2}$, VD/VT, and RR and lower VT during running compared with cycling (Tables 1 and 2). RER showed no significant difference throughout the trials. HR increased significantly during successive R of C-R.

\section{DLco measurements}

DLco measured 10 min after the end of $\mathrm{C}-\mathrm{R}$ and $\mathrm{R}-\mathrm{C}$ decreased significantly when compared to rest values, $\mathrm{p}<0.01$, Table 2 .

Table 2 Arterialised blood gas components $\left(\mathrm{PaO}_{2}, \mathrm{PaCO}_{2}, \mathrm{PAO}_{2}\right.$, [A-a]DO 2 , and pH), alveolar ventilation ( $\left.\mathrm{VA}\right)$ and VD/VT at rest and during C-R and R-C. DLco measured at rest and 10 min after each trial

\begin{tabular}{|c|c|c|c|c|c|c|}
\hline & Rest & $C$ & $R$ & Rest & $R$ & $C$ \\
\hline $\mathrm{PaO}_{2}(\mathrm{~mm} \mathrm{Hg})$ & $\begin{array}{r}104.4 \\
7.7\end{array}$ & $\begin{array}{c}94.1^{*} \\
8.4\end{array}$ & $\begin{array}{c}88.7^{*} \# \\
6.0\end{array}$ & $\begin{array}{r}107.6 \\
8.8\end{array}$ & $\begin{array}{c}86.6^{*} \\
7.3\end{array}$ & $\begin{array}{c}91.4^{*} \# \\
5.4\end{array}$ \\
\hline $\mathrm{PaCO}_{2}(\mathrm{~mm} \mathrm{Hg})$ & $\begin{array}{r}38.5 \\
1.4\end{array}$ & $\begin{array}{c}33.1^{*} \\
3.3\end{array}$ & $\begin{array}{c}32.8^{*} \\
3.9\end{array}$ & $\begin{array}{r}38.7 \\
2.1\end{array}$ & $\begin{array}{r}36.7 \\
2.0\end{array}$ & $\begin{array}{r}35.7 \\
3.3\end{array}$ \\
\hline$\dot{V A}\left(I \cdot \mathrm{min}^{-1}\right)$ & $\begin{array}{r}13.3 \\
1.3\end{array}$ & $\begin{array}{c}95.2^{*} \\
1.3\end{array}$ & $\begin{array}{c}84.1^{*} \# \\
1.3\end{array}$ & $\begin{array}{r}11.6 \\
1.2\end{array}$ & $\begin{array}{c}71.9^{*} \\
2.2\end{array}$ & $\begin{array}{c}82.0 * \# \\
1.4\end{array}$ \\
\hline VD/VT (\%) & $\begin{array}{r}37.6 \\
1.4\end{array}$ & $\begin{array}{r}16.2 \\
1.4\end{array}$ & $\begin{array}{c}32.3^{*} \# \\
1.5\end{array}$ & $\begin{array}{r}38.2 \\
1.1\end{array}$ & $\begin{array}{c}36.9^{*} \\
1.9\end{array}$ & $\begin{array}{c}17.3 \# \\
2.0\end{array}$ \\
\hline $\mathrm{PAO}_{2}(\mathrm{~mm} \mathrm{Hg})$ & $\begin{array}{r}115.8 \\
1.2\end{array}$ & $\begin{array}{c}119.4^{*} \\
2.0\end{array}$ & $\begin{array}{c}121.2^{*} \\
2.0\end{array}$ & $\begin{array}{r}116.8 \\
0.8\end{array}$ & $\begin{array}{r}117.1 \\
1.0\end{array}$ & $\begin{array}{r}118.2 \\
1.6\end{array}$ \\
\hline$(A-a) D_{2}(m m H g)$ & $\begin{array}{r}11.4 \\
2.8\end{array}$ & $\begin{array}{c}24.6^{*} \\
3.6\end{array}$ & $\begin{array}{c}33.2^{*} \# \\
2.1\end{array}$ & $\begin{array}{l}9.2 \\
3.8\end{array}$ & $\begin{array}{c}30.5^{*} \\
2.3\end{array}$ & $\begin{array}{c}26.7^{*} \\
1.6\end{array}$ \\
\hline$D L c o\left(\mathrm{ml} \cdot \min \cdot \mathrm{mm} \mathrm{H} g^{-1}\right)$ & $\begin{array}{r}37.6 \\
1.0\end{array}$ & & $\begin{array}{c}33.3^{*} \\
1.1\end{array}$ & $\begin{array}{r}39.1 \\
1.4\end{array}$ & & $\begin{array}{c}32.4^{*} \\
1.5\end{array}$ \\
\hline
\end{tabular}

Values are mean \pm SD. ${ }^{*} \mathrm{p}<0.05$ significantly different to rest. \# $\mathrm{p}<0.05$ significantly different to precedent exercise 


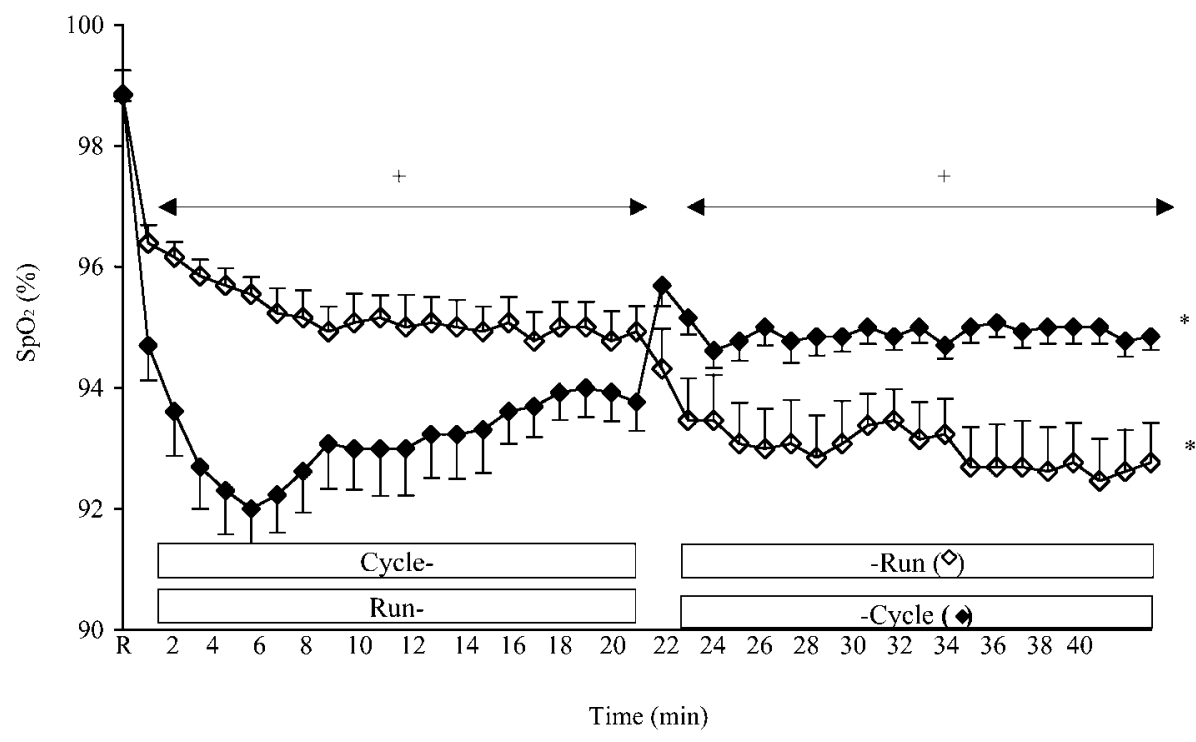

Fig. 1 Percent $\mathrm{SpO}_{2}$ values during the cyclerun trial (C-R: $\diamond)$ and the run-cycle trial (R-C: -). + Significantly different between the first segment of each trial, i.e., C of C-R and R of $\mathrm{R}-\mathrm{C}$ or the second segment of each trial, i.e., C of R-C and R of C-R trials ( $p>0.01)$. ${ }^{*}$ Significantly different within trials between the first and second segments $(\mathrm{p}<0.01)$.

Time $(\min )$

Table $3 \mathrm{SpO}_{2}$ and ventilatory parameters recorded during the two complementary trials in three triathletes. Cycling consisted of 10 min of cycling with a spontaneous breathing pattern ( $C_{1}$ followed by 10 min of cycling with an imposed breathing pattern corresponding to that of running $\left(C_{R}\right)$, then 5 min of cycling with spontaneous breathing pattern $\left(C_{2}\right)$. Running consisted of 10 min of running with a spontaneous breathing pattern $\left(R_{1}\right)$, followed by 10 min of running with a breathing pattern similar to that of cycling $\left(R_{C}\right)$, then 5 min of running with spontaneous breathing pattern $\left(R_{2}\right)$

\begin{tabular}{|c|c|c|c|c|c|c|}
\hline \multirow[b]{2}{*}{ Parameters } & \multicolumn{3}{|l|}{ Cycling } & \multicolumn{3}{|l|}{ Running } \\
\hline & $C_{1}$ & $C_{R}$ & $C_{2}$ & $R_{1}$ & $R_{C}$ & $R_{2}$ \\
\hline \multirow[t]{2}{*}{$\mathrm{SpO}_{2}(\%)$} & 95.2 & 95.7 & 95.1 & 94.2 & 95.2\# & 93.8 \\
\hline & 0.7 & 0.7 & 0.8 & 0.2 & 1.2 & 1.0 \\
\hline \multirow{2}{*}{$\dot{\mathrm{V}} \mathrm{O}_{2}\left(\mathrm{ml} \cdot \mathrm{min}^{-1} \cdot \mathrm{kg}^{-1}\right)$} & 51.5 & 54.7 & 52.9 & 52.6 & 56.4 & 54.9 \\
\hline & 3.8 & 1.9 & 3.8 & 0.9 & 1.6 & 0.8 \\
\hline \multirow[t]{2}{*}{$\dot{V} E\left(I \cdot \min ^{-1}\right)$} & 72.8 & 95.0 & 81.6 & 85.2 & 95.0 & 106.4 \\
\hline & 11.4 & 18.9 & 16.9 & 4.2 & 4.0 & 6.5 \\
\hline \multirow[t]{2}{*}{$V T(m l)$} & 2292 & 1821 & 2122 & 1938 & 2500 & 2081 \\
\hline & 295 & 204 & 291 & 238 & 195 & 239 \\
\hline \multirow[t]{2}{*}{$R R\left(\right.$ breath $\cdot \mathrm{min}^{-1}$ ) } & 32.0 & 52.3 & 39.0 & 44.7 & 38.4 & 52.0 \\
\hline & 3.5 & 5.7 & 6.9 & 7.3 & 1.6 & 7.3 \\
\hline
\end{tabular}

Values are mean $\pm S D$. \# $p<0.05$ significantly higher to $R$

\section{Complementary experiment}

\section{Exercise intensities and respiratory parameters}

Similar $\dot{\mathrm{VO}}_{2}$, $\dot{\mathrm{V}}$, VT, and RR were observed during this complementary experiment when compared with the values of the C-R and R-C trials, as shown in Table $\mathbf{3}$ in comparison with Table 1. In addition, no statistical differences were observed when the VT and $R R$ of running was imposed during $C_{R}$, or inversely when the VT and RR of cycling was imposed during $R_{C}$.

\section{Percent $\mathrm{SpO}_{2}$}

During the entire complementary experiment, $\mathrm{SpO}_{2}$ showed a significant decrease from rest values $(\mathrm{p}<0.05)$. Moreover, when the breathing pattern of cycling was imposed during running, the arterial hypoxemia was partially reduced, whereas the breathing pattern of running failed to worsen arterial hypoxemia during cycling. Thus, within the running trial, $\mathrm{R}_{C}$ presented a significant increase in $\mathrm{SpO}_{2}$ compared with the $\mathrm{R}_{1}$ and $\mathrm{R}_{2}$ values (Table 3; Fig. 2).

\section{Discussion}

The present study showed that constant submaximal running induced greater arterial hypoxemia than cycling performed at a similar metabolic rate. The breathing pattern of running was characterised by a higher respiratory rate and lower tidal volume than that of cycling. Exercise-induced arterial hypoxemia is multifactorial and is known to involve relative hypoventilation and/ or altered pulmonary gas exchanges. Our results strongly suggest that relative hypoventilation caused the higher EIAH during running, while the ventilation-perfusion ratio acted as a protective mechanism for the reduced EIAH noted during cycling; both mechanisms were accompanied with an alteration in pulmonary diffusing capacity.

The $\mathrm{VO}_{2}$ monitoring during the trials eliminated $\mathrm{O}_{2}$ demand as a cause of the greater drop in $\mathrm{SpO}_{2}$ during running, as previously reported by Rasmussen et al. [28]. In fact, these authors reported 


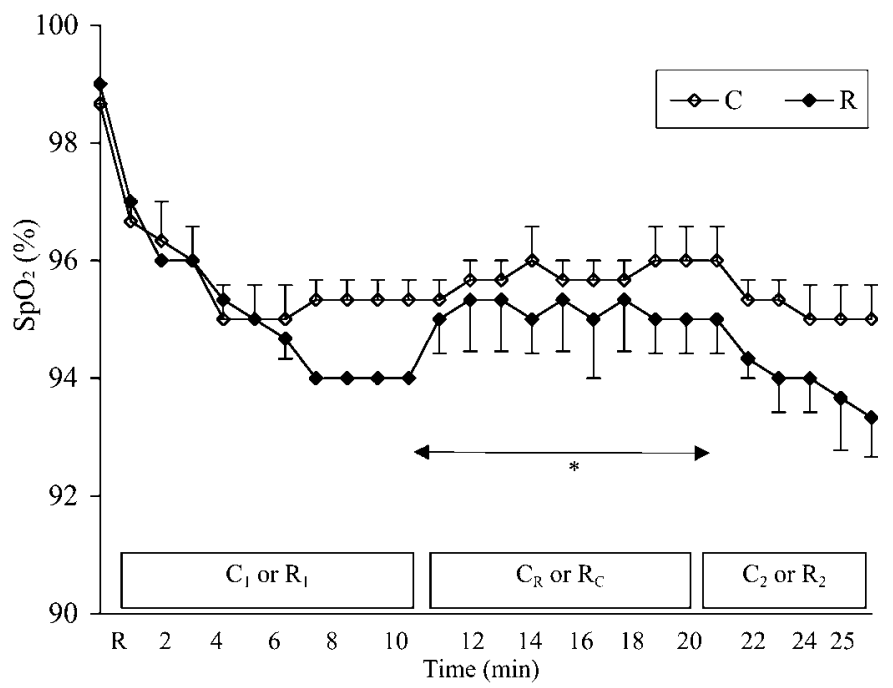

Fig. 2 Percent $\mathrm{SpO}_{2}$ values obtained during $\mathrm{C}(\diamond)$ and $\mathrm{R}(\bullet)$ from complementary experiments in 3 triathletes. During the 25 min of $C$ or $R$, the triathletes exercised for 10 min with a spontaneous breathing pattern $\left(C_{1}\right.$ or $\left.R_{1}\right)$; then for the next 10 min they cycled with the running breathing pattern $\left(C_{R}\right)$ or ran with the cycling breathing pattern $\left(R_{C}\right)$. They then finished the trial with their initial spontaneous breathing pattern $\left(C_{2}\right.$ or $\left.R_{2}\right)$. * Significantly increased during $R_{C}$ when compared to $R_{1}$ and $R_{2}, p<0.05$

higher EIAH during running and rowing compared with arm cranking in a 6-min "all-out" test, and they linked the difference in $\mathrm{SpO}_{2}$ with the amount of recruited muscle mass - and thus with $\mathrm{O}_{2}$ demand - which differed between ergometers. Recently, other studies $[10,17,30]$ have reported higher EIAH during treadmill running compared with ergometer cycling at maximal and submaximal exercise. Because of the heterogeneity of the populations (runners, cyclists, triathletes, soccer players, and swimmers) and/or the use of ergometers that were either more or less familiar to the athletes, the authors did not observe similar $\mathrm{VO}_{2 \max }[10]$ or significant EIAH [17]. In the present study, we selected a homogeneous population of highly trained triathletes (some of them were on the French national team) and we used constant load exercise and the same metabolic rate during both running and cycling.

According to Dempsey and Wagner [6], the absolute individual $\mathrm{SpO}_{2}$ of the present triathletes corresponded to moderate (8893\%) EIAH during incremental testing on a cycle ergometer, and thus to mild (93-95\%) and moderate EIAH during the cycling and running segments of the trials, respectively. These results agree with recent studies of our group that showed similar drops in $\mathrm{SpO}_{2}$ during running and cycling $[8,9]$. It should be noted that the two trials consisted of $40 \mathrm{~min}$ each of steady-state exercise and that they showed low variability in $\mathrm{SpO}_{2}$ (Fig. 1). This was in contrast with the reports on $\mathrm{SpO}_{2}$ of fast-increment or shortmaximal protocols of other studies in the literature $[13,30]$ and led us to assume that EIAH was present throughout the entire trials.

Whatever the exercise modality, EIAH has mainly been attributed to relative hypoventilation [5] and/or an alteration in pulmonary gas exchange, i.e., ventilation/perfusion mismatching and/or diffusion limitation [4]. Alterations in pulmonary diffus- ing capacity have frequently been described in triathletes during submaximal isolated or successive cycle-run or run-cycle trials $[8,9,18]$. The present drops in DLco confirmed these earlier results (Table $\mathbf{2}$ ) and could be considered to have contributed to the development of EIAH. However, the similar drops of DLco cannot totally explain the differences of EIAH observed between the $\mathrm{C}$ and $\mathrm{R}$ segments, mainly inside trials.

VA/Q mismatching may have contributed to the aggravation of $\mathrm{EIAH}$, mainly during the $\mathrm{R}$ segments. Indeed, $(\mathrm{A}-\mathrm{a}) \mathrm{DO}_{2}$, which reflects $\dot{V} A / Q$ mismatching [27], greatly increased during and within each trial, resulting in higher $(\mathrm{A}-\mathrm{a}) \mathrm{DO}_{2}$ for $\mathrm{R}$ of $\mathrm{C}-\mathrm{R}$ and a trend for R of R-C. Unfortunately, we cannot totally explain the differences in EIAH observed in the present study by $\dot{V A} / \mathrm{Q}$ mismatching, despite its presence.

Relative hypoventilation has recently been suggested as a predominant factor at submaximal metabolic rate. It was noted in all highly trained athletes $[4,26]$, though in some athletes it was corrected at maximal intensity [7].

The finding of greater EIAH with higher VE during treadmill running than cycling at submaximal intensity did not agree with previous studies that showed relative hypoventilation concomitant with low VंE $[7,10,27,30]$. In our study, running was characterised by a specific breathing pattern: high RR and low VT. Such a breathing pattern, frequently termed rapid shallow breathing $[3,33]$, has been reported to increase the VD/VT ratio, and therefore to induce a relative hypoventilation [3]. In contrast to running, cycling was characterised by a lower $\dot{V} E$, which has also been described as a possible cause of relative hypoventilation. Running and cycling would thus both be characterised by a very suspicious increase in VD/VT and a decrease in VA, probably in relation with a different breathing pattern. We therefore hypothesised that running performed with a breathing pattern similar to that of cycling (VT and RR) would increase $\mathrm{SpO}_{2}$, whereas ergometer cycling performed with a breathing pattern similar to that of running (VT and RR) would decrease it.

To test this hypothesis, two complementary randomised trials were performed by three volunteer triathletes, as detailed in the Methods section. As expected, running performed with a breathing pattern similar to that of cycling, i.e., $\mathrm{R}_{\mathrm{C}}$, induced a significant increase in $\mathrm{SpO}_{2}$ up to that reported for cycling during C-R and R$\mathrm{C}$ (Fig. 2). This result showed that a reduction in RR and a rise in VT during running improved $\mathrm{SpO}_{2}$, probably by increasing VA. We thus assumed that the breathing pattern of running was responsible for the greater decrease in $\mathrm{SpO}_{2}$ rather than running perse.

In contrast, the cycling performed with the breathing pattern similar to that of running, i.e., $C_{R}$, failed to worsen the decrease in $\mathrm{SpO}_{2}$ (Table 3; Fig. 2). We thus speculate that the "crouched position" [14] of triathletic cycling, using a specific handlebar, served to protect from moderate EIAH. A recent study in fact showed increased homogeneity of the $\dot{V} A / Q$ distribution in the prone position compared with the supine position [23]. In addition, the authors found an increase in $\mathrm{PaO}_{2}$ with a decreased coefficient of variation of $\dot{V} A$ in the prone position. The "crouched position" may have pathophysiological effects quite similar to 
those of the prone position - particularly improved $\dot{V A} / \mathrm{Q}$ - and thus may maintain $\mathrm{SpO}_{2}$ in spite of an unfavourable breathing pattern.

From a methodological point of view, the measurement of $\mathrm{SpO}_{2}$ via ear oximeter had the great technical advantage of non-invasiveness. EIAH is now commonly studied with a pulse oximetry system because of its high reliability and non-invasiveness, as described in the Methods section [10,22,27], although some studies do claim that pulse oximetry is not reliable for this use $[2,12,29,34]$. Our group demonstrated the accuracy of pulse oximetry when used in highly trained athletes, with a minimum drop of $4 \%$ from rest values in addition to a persistance of $\mathrm{SpO}_{2}$ values for $3 \mathrm{~min}$ throughout a steady-state exercise [22,27]. Pulse oximetry did, however, limit the interpretation of our results so in the present study we completed ear oximetry with blood gas measurement. To our knowledge, only two studies have investigated EIAH in athletes during cycling and/or running in short submaximal ( 5 min) and maximal exercises using arterial catheterisation and a rectal thermocouple $[13,30]$. The present experiment already required two 40-min trials and a change in apparatus so we did not want to further impose an invasive method on our subjects; we instead chose to use pulse oximetry and arterialised blood gas measurements, as previously reported in triathletes [18]. Because of the relationship between $\mathrm{PaO}_{2}$ and rectal temperature, the succession of running and cycling could have aggravated the $\mathrm{PaO}_{2}$ decrease during the last segment of $\mathrm{C}$ $\mathrm{R}$ and R-C. Interestingly, $\mathrm{PaO}_{2}$ and $\mathrm{SpO}_{2}$ relative to running and cycling were similar whatever the position of the modalities within the trials, suggesting that the blood temperature increase throughout the trials was not sufficient to have an impact on the $\mathrm{PaO}_{2}$ and $\mathrm{SpO}_{2}$ results. We are aware that only three triathletes for the complementary trials pose a drawback to interpreting the results. However, the triathletes' high training and high level of compliance need to be taken into account and suggest that the bias was probably minimal. Moreover, the results are presented here as descriptive data.

The findings of the present study confirmed the trend of previous works $[10,17,30]$ and demonstrated that EIAH is dependent on exercise modality. The similar variation in $\mathrm{PaO}_{2}$ and $\mathrm{SpO}_{2}$ exhibited during running and cycling, whatever the position in the C-R and $\mathrm{R}-\mathrm{C}$ successions, suggested that they each induced specific pathophysiological mechanisms for EIAH development. Pulmonary diffusion alterations and/or $\dot{V A} / \mathrm{Q}$ mismatching probably contribute to the overall mechanism, while the relative hypoventilation observed during running appeared to be linked to breathing pattern and likely had the major effect on the EIAH observed. In contrast, the breathing pattern noted during cycling did not appear to be linked to the drop in $\mathrm{SpO}_{2}$. We suggest that the better VA/Q distribution due to the "crouched-position" on the bicycle may have prevented further EIAH development.

In conclusion, the present study showed that exercise-induced arterial hypoxemia is dependent on the exercise modality. High level triathletes performed cycle-run and run-cycle trials at a similar metabolic rate that was close to their training intensities. Running induced greater arterial hypoxemia than cycling, whatever the position of the modality during trials, and a specific ventilatory response to each modality was noted as well. Based on
Zeitschrift IJSM sm290

AK-PDF tt.mm.jj

Satzbetrieb Ziegler + Müller

ef-Upload tt.mm.jj Thieme/Hentze

Datum 21.01.2005

these results, practical advice for triathletes and coaches would be to pay particular attention to breathing pattern during the run segment of training and races in order to limit the potentially deleterious effect of exercise-induced arterial hypoxemia.

\section{Acknowledgments}

The authors wish to give special thanks to the triathletes for their excellent cooperation.

\section{References}

${ }^{1}$ Beaver WL, Wasserman K, Whipp BJ. A new method for detecting anaerobic threshold by gas exchange. J Appl Physiol 1986; 60: 2020-2027

2 Brown DD, Knowlton RG, Sanjabit PB, Szurgot BT. Re-examination of exercise-induced hypoxaemia in highly trained athletes. $\mathrm{Br} \mathrm{J}$ Sports Med 1993; 27: 167-170

${ }^{3}$ Caillaud C, Anselme F, Mercier J, Préfaut C. Pulmonary gas exchange and breathing pattern during and after exercise in highly trained athletes. Eur J Appl Physiol 1993; 67: 431 - 437

${ }^{4}$ Caillaud C, Serre-Cousine O, Anselme F, Capdevilla X, Préfaut C. Computerized tomography and pulmonary diffusing capacity in highly trained athletes after performing a triathlon. J Appl Physiol 1995; 79: $1226-1232$

5 Dempsey JA, Hanson P, Hendersen K. Exercise induced arterial hypoxemia in healthy human subjects at sea level. J Appl Physiol 1984; 355 : $161-175$

${ }^{6}$ Dempsey JA, Wagner PD. Exercise-induced arterial hypoxemia. J Appl Physiol 1999; 87: 1997-2006

7 Durand F, Mucci P, Préfaut C. Evidence for an inadequate hyperventilation inducing arterial hypoxemia at submaximal exercise in all highly trained endurance athletes. Med Sci Sports Exerc 2000; 32: 926-932

${ }^{8}$ Galy O, Hue O, Boussana A, Le Gallais D, Préfaut C. Cardiorespiratory responses and blood lactate during an experimental run-cycle transition in duathletes. Int J Sports Med 2002; 23: $162-167$

${ }^{9}$ Galy O, Hue O, Boussana A, Peyreigne C, Mercier J, Prefaut C. Blood rheological responses to running and cycling: a potential effect on the arterial hypoxemia of hughly trained athletes? Int J Sports Med 2004; in press

10 Gavin T, Stager MJ. The effect of exercise modality on exercise-induced hypoxemia. Respir Physiol 1999; 115: 317 - 323

11 Hanel B, Clifford P, Secher N. Restricted postexercise pulmonary diffusion capacity does not impair maximal transport for $\mathrm{O}_{2}$. J Appl Physiol 1994; 77: $2408-2412$

12 Harms CA, Stager JM. Low chemoresponsiveness and inadequate hyperventilation contribute to exercise-induced hypoxemia. J Appl Physiol 1995; 79: 575-580

${ }^{13}$ Harms CA, McClaran SR, Nickele GA, Pegelow DF, Nelson WB, Dempsey JA. Effect of exercise-induced arterial $\mathrm{O}_{2}$ desaturation on $\mathrm{VO}_{2 \max }$ in women. Med Sci Sports Exerc 2000; 32: 1101 - 1108

14 Hill NS, Jacoby C, Farber HW. Effect of an endurance triathlon on pulmonary function. Med Sci Sports Exerc 1991; 23: 1260-1264

15 Holmgreen A, Linderholm H. Oxygen and carbon dioxide tensions of arterial blood during heavy and exhaustive exercise. Acta Physiol Scand 1958; 44: $203-215$

${ }^{16}$ Holmgreen A, Mc Ilroy MB. Effects of body temperature on arterial blood gas tensions and pH during exercise. Respir Physiol 1991; 83: $143-154$

17 Hopkins SR, Barker RC, Brusteart TD, Gavin TP, Entin P, Olfert IM, Veisel S, Wagner PD. Pulmonary gas exchange during exercise in women: effects of exercise type and work increment. J Appl Physiol 2000; 89: $721-730$

${ }^{18}$ Hue O, Le Gallais D, Chollet D, Boussana A, Préfaut C. Ventilatory responses during experimental cycle-run transition in triathletes. Med Sci Sports Exerc 1999; 10: 1422-1428 
${ }^{19}$ Hue O, Le Gallais D, Préfaut C. Ventilatory threshold and maximal oxygen uptake in present triathletes. Can J Appl Physiol 2000; 25: $102-113$

${ }^{20}$ Kreider RB, Boone T, Thompson WR, Burke S, Cortes CW. Cardiovascular and thermal responses of triathlon performance. Med Sci Sports Exerc 1988; 20: $385-390$

21 Martin D, Powers S, Cicale M, Collop N, Huang D, Criswell D. Validity of pulse oxymetry during exercise in elite endurance athletes. J Appl Physiol 1992; 72: $455-458$

22 Mucci P, Prioux J, Hayot M, Ramonatxo M, Préfaut C. Ventilation response to $\mathrm{CO}_{2}$ and exercise-induced hypoxemia in master athletes. Eur J Appl Physiol 1998; 77: 343 - 351

23 Mure M, Domino KB, Lindahl SGE, Hlastala MP, Altemeier WA, Glenny RW. Regional ventilation-perfusion distribution is more uniform in the prone position. J Appl Physiol 2000; 88: 1076-1083

24 Powers SK, Martin D, Dodd S. Exercise-induced hypoxemia in elite endurance athletes. Incidence, causes and impact on $\mathrm{VO}_{2 \max }$. Sports Med 1993; 16: $14-22$

25 Préfaut C, Karaouni B, Ramonatxo M, Michel B, Macabiès J. A one-year double-blind follow-up of blood gas tensions and haemodynamics in almitrine bismesylate therapy. Eur Respir J 1988; 1: 41 - 50

${ }^{26}$ Préfaut C, Anselme F, Caillaud C, Masse-Biron J. Exercise-induced hypoxemia in older athletes. J Appl Physiol 1994; 76: 120-126

27 Préfaut C, Durand F, Mucci P, Caillaud C. Exercise-induced hypoxemia in athletes: a review. Sports Med 2000; 30: 47-61
Zeitschrift IJSM sm290

AK-PDF tt.mm.j

Satzbetrieb Ziegler + Müller Verlag Thieme/Hentze ef-Upload tt.mm.j

Datum 21.01.2005

28 Rasmussen J, Hanel B, Diamant B, Secher NH. Muscle mass effect on arterial desaturation after maximal exercise. Med Sci Sports Exerc 1991; 23: 1349 - 1352

29 Rice AJ, Scroop GC, Gore CJ, Thornton AT, Chapman MJ, Greville HW, Holmes MD, Scicchitano R. Exercise-induced hypoxemia in highly trained cyclists at 40\% peak oxygen uptake. Eur J Appl Physiol 1999; 79: $353-359$

30 Rice AJ, Scroop GC, Thornton AT, Mc Naughton NS, Rogers KJ, Chapman MJ, Greville HW, Scicchitano R, Gore CJ. Arterial hypoxemia in endurance athletes is greater during running than cycling. Respir Physiol 2000; 123: 235-246

31 Rowell LB, Taylor HL, Wang Y, Carlson WB. Saturation of arterial blood with oxygen during maximal exercise. J Appl Physiol 1964; 19: 284 286

32 Stager JM, Cordain L, Malley J, Wigglesworth J. Arterial desaturation during arm exercise with controlled frequency breathing. J Swim Res 1989; $1: 5-10$

33 Younes M, Burrks J. Breathing pattern during and after exercise of different intensities. J Appl Physiol 1985; 59: 898-908

${ }^{34}$ Williams JH, Powers SK, Stuart MK. Hemoglobin desaturation in highly trained athletes during heavy exercise. Med Sci Sports Exerc 1986; 18: $168-173$

35 Wilkinson L. Systat: The System for Statistics. Evasion, IL: Systat Inc, 1990

Author: please check if $\dot{V} \ldots$ and $V$... have been assigned correctly in the different expressions 